\title{
An example of operation for a partly manned Antarctic geomagnetic observatory and the development of a radio link for data transmission
}

\author{
J. Miquel Torta $\left({ }^{1}\right)$, Santiago Marsal $\left({ }^{1}\right)$, John C. Riddick $\left({ }^{1}\right)$, Carles Vilella $\left({ }^{2}\right)$, David Altadill $\left({ }^{1}\right)$, \\ Estefania Blanch $\left({ }^{1}\right)$, Oscar Cid $\left({ }^{1}\right)$, Joan J. Curto $\left({ }^{1}\right)$, Angelo De Santis $\left({ }^{3}\right)$, Luis R. Gaya-Piqué $\left({ }^{4}\right)$, \\ Joan Mauricio $\left({ }^{2}\right)$, Joan L. Pijoan $\left({ }^{2}\right)$, J. Germán Solé $\left({ }^{1}\right)$ and Arantza Ugalde $\left({ }^{1}\right)$ \\ (') Observatori de l'Ebre, CSIC - Universitat Ramon Llull, Roquetes, Spain \\ ${ }^{(2)}$ Enginyeria i Arquitectura La Salle, Universitat Ramon Llull, Barcelona, Spain \\ $\left(^{3}\right)$ Istituto Nazionale di Geofisica e Vulcanologia, Roma, Italy \\ $\left(^{4}\right)$ Equipe de Géomagnétisme, Institut de Physique du Globe de Paris - CNRS, Paris, France
}

\begin{abstract}
The experience acquired from more than ten years of operation of an Antarctic geomagnetic observatory is described along with the development of data transmission facilities. The observatory was deployed at the Spanish Antarctic Station in 1996. The main instrument was an Overhauser magnetometer deployed in dual axis Helmholtz coils, a $\delta \mathrm{D} / \delta \mathrm{I}$ configuration. The site is only manned during the summer, with the magnetometer left recording throughout the rest of the year. During the 2007-2008 survey the observatory instrumentation has been upgraded with a DMI suspended triaxial fluxgate magnetometer, new sampling hardware and data logging software. Both sampling and timing are carried out under the control of a PIC based microcontroller and GPS receiver. Data presentation, transmission and archiving are performed under the control of a low power embedded PC. For real time access to the data two options have been provided and rigorously tested during the last 10 years: METEOSAT and GOES Data Collection Systems, and recently, a high frequency (HF) digital radio-link, using ionospheric propagation between Antarctica and Spain, has been developed. This latest transmission system is being continuously upgraded, and it would be possible to extend its application to other remote stations. Measurements have been made during the last four years in order to determine the channel characteristics and its variability, mainly the multipath and Doppler spread and the link availability for a given SNR in the receiver. These measurements are being used to design the physical layer of a radiomodem intended to maximize the link capacity keeping the emitted power low.
\end{abstract}

Key words geomagnetic observatories - geophysical instrumentation - data transmission - HF radio

\section{Introduction}

A geomagnetic observatory is an installation where the geomagnetic vector is continu-

Mailing address: Dr. J. Miquel Torta, Observatori de l'Ebre, CSIC - Universitat Ramon Llull, Horta Alta 38, 43520 Roquetes, Spain; e-mail: jmtorta@ obsebre.es ously observed for an extended period of time (Rasson and van Loo, 2007). Observatories are the very first stage of the scientific process of measuring the raw data, which is used by the scientific community for geophysical studies. As their aim is to provide the users with calibrated geomagnetic data of high accuracy, there is a requirement for the measurements of the magnetic field vector to be made to an accuracy of better than $5 \mathrm{nT}$. This specification immediately limits the choice of instruments (which must provide a combination of variometer data and absolute measurements) to a few types. For 
variometer data, the standards require a resolution of $0.1 \mathrm{nT}$, a dynamic range between 6000 $\mathrm{nT}$ and $8000 \mathrm{nT}$ depending on latitude, a band pass from DC to $0.1 \mathrm{~Hz}$, a sampling rate of 1 $\mathrm{Hz}$, a thermal stability lower than $0.25 \mathrm{nT} /{ }^{\circ} \mathrm{C}$, a long term drift lower than $5 \mathrm{nT} /$ year and Gaussian data filtering to provide minute data (INTERMAGNET, 2008).

The sensors used by modern digital variometers are based either on fluxgates, with preferably a suspended sensor; or scalar magnetometers deployed in Helmholtz coils. Suspended fluxgates have higher mechanical stability and sampling rate, but worse thermal stability.

Absolute measurements are universally being made with proton precession magnetometers (PPM) for the measurement of the total field intensity, $F$, and with D/I fluxgate theodolites (DI-flux) for the measurement of the angular geomagnetic elements declination $(D)$ and inclination $(I)$. From the inter-comparison of instruments made at the Workshops on geomagnetic observatories, we can conclude that the best DI-flux instruments can measure with accuracies of some arc seconds, while those of the PPM are of some tenths of nanotesla (Torta, 2003).

To encourage the adoption of those modern standards, at the beginning of the 1990's the INTERMAGNET program was instituted. Its participants comprise most of the present digital magnetic observatories, and it has the added objective of facilitating the interchange of observatory data in real or quasi real time. Nevertheless, the current distribution of observatories presents an uneven distribution. The density is clearly correlated with the land-sea distribution, but there is also a North-South bias indicating an economic influence. With the purpose of improving their global coverage, some initiatives to locate instruments on the sea bottom are appearing (e.g. Utada and Shimizu, 2001; De Santis et al., 2006). This, along with the deployment of automatic stations in remote islands, can help to improve that coverage. But the perfectly stable automatic station has not yet been developed, so that frequent visits to the sites to perform absolute measurements are still needed. Solutions are presently being investigated, for example the use of an automatic DI-flux (Van Loo and Rasson, 2006) or of a device based on the rotation of a three-component fluxgate magnetometer about precisely monitored axes (Auster et al., 2007).

With the aim of contributing to the worldwide net of geomagnetic observatories, in December 1996 a geomagnetic observatory was deployed at the Spanish Antarctic Base Juan Carlos I (62 $\left.39^{\prime} 44^{\prime \prime} \mathrm{S}, 60^{\circ} 23^{\prime} 41^{\prime \prime} \mathrm{W}\right)$, located on Livingston Island, in the South Shetland Islands archipelago. An estimation of the particular lithospheric anomaly field recorded at this site is given in Torta et al. (1999). The observatory has been operating reliably since its installation, and the International Association of Geomagnetism and Aeronomy (IAGA) has recognised it and given it the code name LIV. Besides its contribution to the monitoring of the secular variation of the magnetic field, this observatory has provided geomagnetic reference data to the surveys carried out in the Bransfield Strait - Antarctic Peninsula region (e.g. Maldonado et al., 2000; Livermore et al., 2000; Catalán et al, 2006), and for the local array of magnetometers deployed in the nearby Deception Island for the detection of volcanomagnetic effects (García et al., 1997).

As well as producing quality data, observatories also have to allow users means of rapid and easy access to the data (see, e.g. Rasson and van Loo, 2007). For real time access to the LIV data two options have been provided and rigorously tested during the last decade: METEOSAT and GOES Data Collection Systems, and recently, a high frequency (HF) digital radio-link using ionospheric propagation between Antarctica and Spain has been developed and tested during the last surveys.

This paper presents the experience gained after more than ten years of operation of LIV magnetic observatory. Section 2 describes this observatory and the facilities used up to November 2007 to automatically transmit the recorded data. Section 3 deals with the upgrade of the instrumentation that was carried out during the 2007-2008 Antarctic survey season. Section 4 provides the description of the new HF digital radio-link. Finally the conclusions extracted from our work are presented, in the 
belief that they will be of utility for other groups operating geophysical stations in remote regions. Since there are many acronyms in the paper, table I provides an acronym glossary to improve the reading speed.

\section{LIV observatory description and operation: The first epoch (1996-2007)}

Livingston Island observatory facilities comprise three huts, which were built using non-magnetic materials. One of them contains the pier for the absolute observations, i.e. for the measurement of absolute $D, I$, and $F$. A sec-

Table I. Acronym glossary.

\begin{tabular}{ll}
\hline A/D & Analog to Digital \\
BER & Bit Error Rate \\
BGS & British Geological Survey \\
D/A & Digital to Analog \\
DDC & Digital Down Converter \\
DI-flux & D/I fluxgate theodolite \\
DMI & Danish Meteorological Institute \\
DUC & Digital Up Converter \\
D/I & Variometer type in use at Liv- \\
& ingston Island Observatory \\
FPGA & Field Programmable Logic Array \\
GIN & Geomagnetic Information Node \\
HF & High Frequency \\
IAGA & International Association of Geo- \\
INTERMAGNET & magnetism and Aeronomy \\
& mabal network of digital geo- \\
LIV & Livingston Island Observatory \\
PIC & Programmable Intelligent Com- \\
PPM & puter \\
QPSK & Proton Precession Magnetometer \\
RAM & Quadrature Phase Shift Keying \\
RTC & Random Access Memory \\
SANDICOM & Real Time Clock \\
SNR & Sounding System for Antarctic \\
VGA & Digital Communications \\
\hline & Signal to Noise Ratio \\
Variable Gain Amplifier \\
\end{tabular}

ond hut contains another pier which supports the sensor and coils of the automatic station, basically a proton magnetometer mounted in coils arranged in a $\delta \mathrm{D} / \delta \mathrm{I}$ configuration. This instrument, based on the polarisation of an Overhauser effect PPM, is used to measure the total field and, by means of a pair of dual axis Helmholtz coils, deployed parallel to the directions given by the local declination and inclination, measures the field changes in the $D$ and $I$ elements. The equipment was developed by the Geomagnetism Group of the British Geological Survey (BGS) in Edinburgh. Its technical details are described by Riddick et al. (1995), and a summarized description of its principles and operation is given by Torta et al. (2001). An IBM compatible PC in the third hut communicates with the magnetometer to control the data acquisition and coil switching using the standard PC serial and parallel interfaces. This third hut also accommodates the electronics which generates stable currents to bias the $\delta \mathrm{D} / \delta \mathrm{I}$ coils. Time synchronisation is provided by a GPS receiver. Taking advantage of the low power requirements of this instrument continuous operation is maintained using a combination of solar cells and wind generators, which charge a battery rack.

Absolute measurements of declination and inclination are made using an ELSEC 810A DIflux. It comprises a single axis fluxgate magnetometer sensor element mounted on a Zeiss 015B non-magnetic theodolite with the electronics package placed in the same hut. The $D / I$ observation procedure is based on the null-field technique. To remove the errors due to the misalignment of the fluxgate sensor and the optical axis of the theodolite, as well as those due to the zero-field offset generated by the control electronics, the observations are made in four positions for each element (see, e.g., Jankowski and Sucksdorff, 1996, or Marsal and Torta, 2007).

The total field values used in the reduction of the absolute observations, necessary to calculate the horizontal $(H)$ and vertical $(Z)$ field intensities, are obtained from the Overhauser effect PPM, when it measures with no polarization of the coils. $F$ measured at the $\delta \mathrm{D} / \delta \mathrm{I}$ site is corrected for the field difference with respect to the absolute site. This site difference is checked 


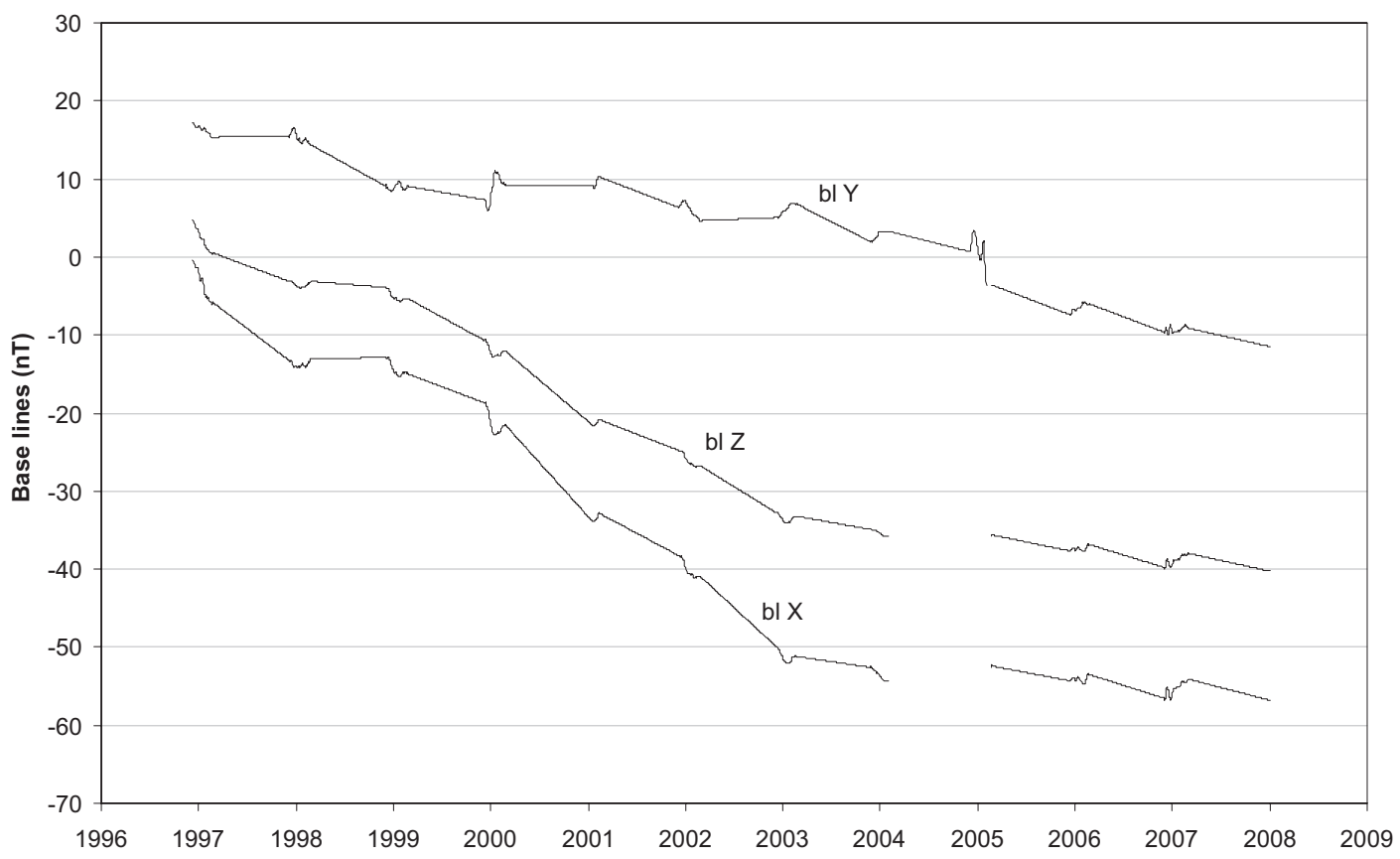

Fig. 1. $\mathrm{X}, \mathrm{Y}$ and $\mathrm{Z}$ baselines adopted for LIV during its complete period of operation. Periods with non-linear baselines centred at the beginning of each year (of around 3 month span on average) correspond to summer Antarctic surveys, i.e. periods with absolute control. The observed differences from the absolute measurements that give rise to the adopted baselines are not plotted because they would be indistinguishable at this temporal scale; they can be found in the corresponding bulletins (Marsal et al., 2007a and references therein). The baselines adopted for the periods between surveys are linear functions with the necessary slopes to pass from the adopted differences at the end of one survey to those of the beginning of the next one. The period without baselines for X and Z corresponds to a failure in the vector magnetometer, from October 2004 to February 2005, that prevented them from being obtained for the whole period between surveys.

annually by making simultaneous measurements of $F$ at the DI-flux pillar using a GEM Systems GSM19 Overhauser PPM, and at the automatic observatory using the existing GEOMAG SM90R Overhauser magnetometer.

Both the variometer and the absolute instruments were installed during December 1996, with continuous recording and the absolute observing program beginning on December 7 , 1996. All measurements made during each summer survey jointly with those relating to the preceding year are summarized in the corresponding bulletins (Marsal et al., 2007a and references therein). Assessments of both the variometer system and the DI-flux absolute magnetometer can be found in Marsal et al. (2007b) and Marsal and Torta (2007), respectively. From these studies it can be concluded that the BGS $\delta \mathrm{D} / \delta \mathrm{I}$ has proved to be a reliable system, presenting some advantages with respect to other magnetometers, such as low temperature dependence and an acceptable shortterm stability. However, effects such as longterm pier instabilities or distortion of the coils alignment can introduce errors if the measurements are not regularly corrected by absolute observations, this being the fundamental problem of some remote observatories and especially of LIV, where absolute measurements can only be carried out for three months every year (see fig. 1). The DI-flux is an excellent instrument to reliably undertake the absolute meas- 


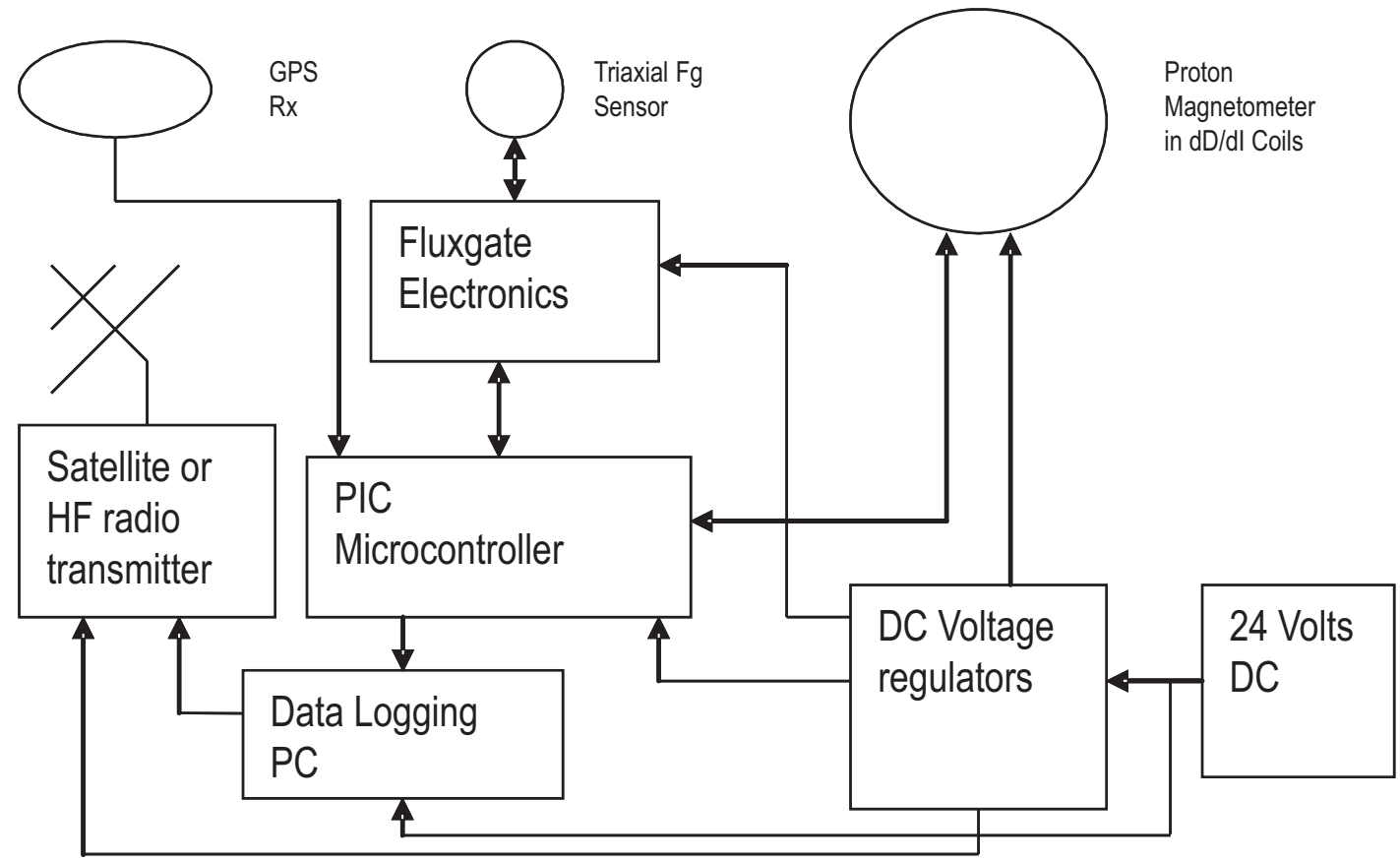

Fig. 2. Block diagram of the new station.

urements of declination and inclination, and for this reason it has become the international standard. Nevertheless, a series of effects limit its accuracy (Marsal and Torta, 2007). Regarding systematic effects, it is in general affected by collimation errors and zero-field offset, which are compensated in the normal observation procedure as stated before. Undesired systematic effects can be detected with a series of control measures, which are regularly made at LIV. As for random effects, their magnitude does not generally exceed 0.1 arcmin for an experienced observer, for either declination or inclination, and can be minimized by a sufficiently long series of measurements.

As the site is only manned during the Austral summer, all scientific staff depart at the end of February each year, but the magnetometers are left operating. The data recorded throughout the winter are retrieved at the beginning of the next survey season. Since the 1999-2000 Survey, data recorded at the Observatory have also been transmitted either via the Meteosat satel- lite to the INTERMAGNET Geomagnetic Information Node (GIN) at Edinburgh, or via the GOES_E satellite to the GIN at Ottawa, and are then forwarded to Ebre Observatory. Unfortunately, the quality of the transmissions deteriorated progressively and at the end of the 20042005 survey it was decided to disable these transmissions in order to save energy necessary for the data acquisition hardware. During 2007 these transmissions were re-instated, and a new type of satellite transmitter has been installed. This facility will be described in Section 3.

\section{Design of the new station}

Despite using INTERMAGNET facilities for the automatic data transmission to Ebre Observatory (Torta et al., 2001), LIV station has not been included in this network yet because it does not fully comply with INTERMAGNET standards outlined in Section 1. For these reasons, during the 2007-2008 Antarctic survey 


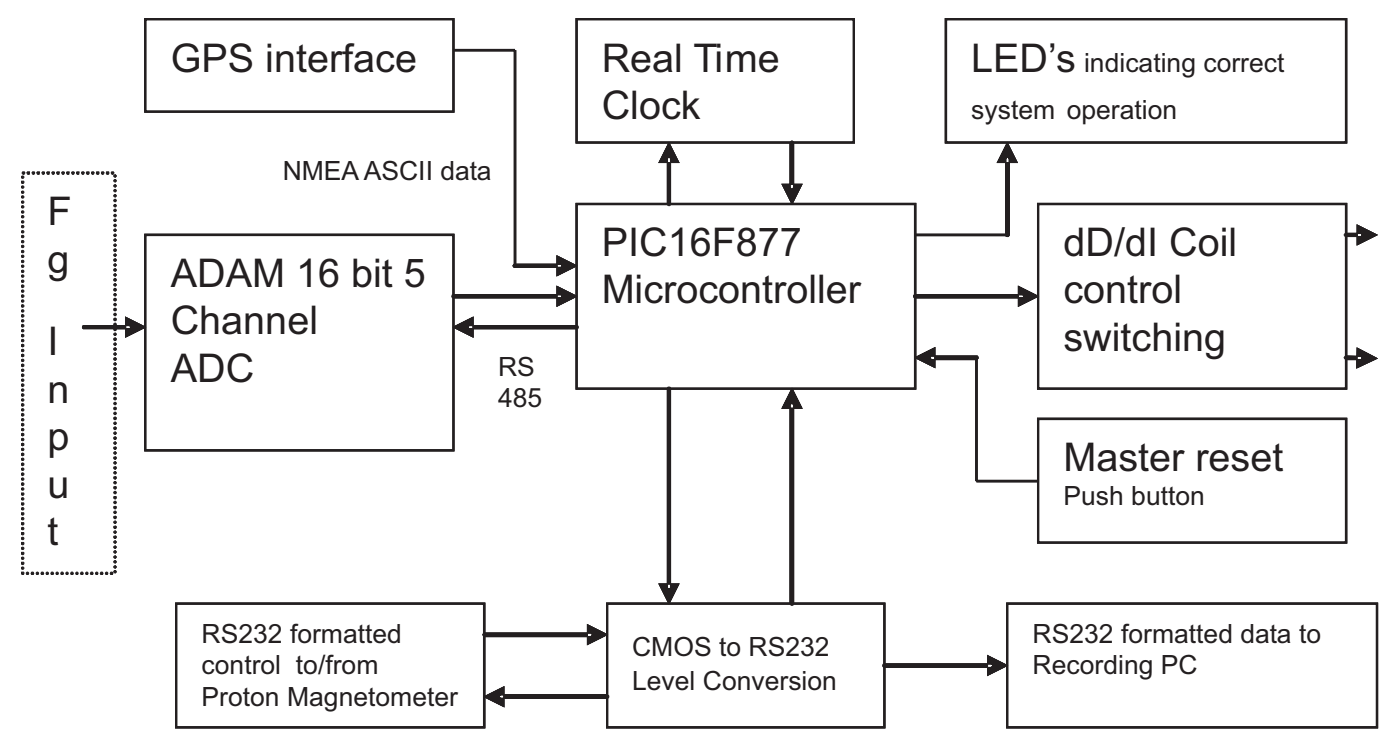

Fig. 3. Controller Block Diagram.

the installation of new sensors and recording hardware was undertaken at LIV.

One of the main reasons the existing LIV system did not meet INTERMAGNET standards was the sampling rate of the proton magnetometer (only 1 sample of $D, I$ and $F$ every minute). To meet the required sampling rate, a tri-axial suspended fluxgate sensor has been installed. Figure 2 shows the design of the new station. The new instrument is a Danish Meteorological Institute (DMI) suspended triaxial fluxgate magnetometer FGE model. It measures intensity changes in the vertical and local magnetic North and East directions. All outputs are analog voltages. Each component must be individually calibrated to determine its actual sensitivity in nT/V. All components have scale values of approximately $320 \mathrm{nT} / \mathrm{V}$. Their dynamic range (translated to magnetic field values) is $\pm 1600 \mathrm{nT}$, giving a $0.05 \mathrm{nT}$ resolution using a 16 bit A/D converter with a \pm 5 $\mathrm{V}$ input range. Taking into account the range of the highest amplitude variations ever recorded at LIV (a drop of around $1300 \mathrm{nT}$ in the magnetic field strength during the main phase of a magnetic storm on 30-31 March, $2001)$, this range was preferred with respect to one having a dynamic range of $\pm 3200 \mathrm{nT}$, but a resolution of just $0.3 \mathrm{nT}$. Initial scale values given by the manufacturers are approximate. Exact values will be derived from on-site calibrations. Sensor and electronics temperatures are also output, with a sensitivity of approximately $10 \mathrm{mV} / \mathrm{K}$.

The fluxgate manufacturers specify the instrument has a temperature coefficient below $0.25 \mathrm{nT} /{ }^{\circ} \mathrm{C}$ for each of the three sensor elements. In order to find out the exact values of the temperature coefficients, a series of tests have been carried out with the final aim of correcting for temperature variations. An analysis of these tests is currently being made.

All sampling and timing are carried out under the control of hardware based on a PIC 16F877 microcontroller and a GPS receiver (fig. 3). This device is a software controlled microprocessor which stores the users program in an $8 \mathrm{kB}$ array of programmable FLASH memory, and is also provided with 368 bytes of RAM for temporary data storage. All inputs and outputs to the device are CMOS levels output through over 30 individually programmable ports operating using a $4 \mathrm{MHz}$ crystal oscillator. Sample timing is synchronised by a GPS receiver, and in the event of loss of GPS synchronisation timing is main- 


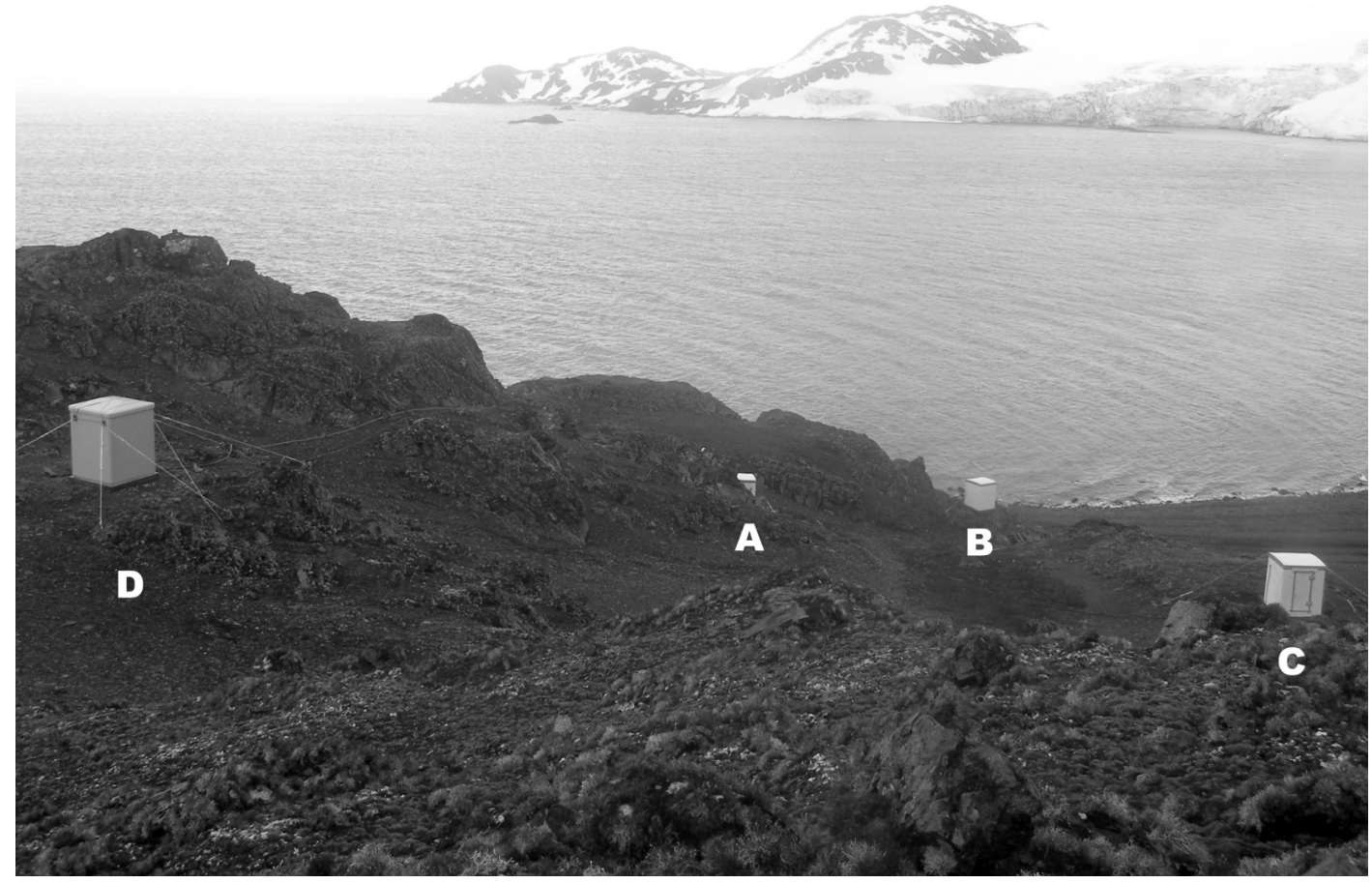

Fig. 4. LIV geomagnetic observatory instrument accommodation. The A, B and C huts correspond to the observatory during 1996-2007. They hold the electronics, the absolute instrument and the D/I magnetometer, respectively. The new hut, D, holds the FGE magnetometer deployed during the 2007-2008 summer survey.

tained using the on-board Real Time Clock (RTC) module.

The data acquisition, storage, monitoring, and transmission processes are supervised using control software developed in $\mathrm{C}$ language, which runs on a low power LINUX-based embedded PC. All data output from the sensors (1second and 10-second fluxgate $H D Z$ ordinates, proton vector data, GPS time, fluxgate temperature) along with PC housekeeping are continuously displayed on the LCD screen. This display is useful for local data monitoring and fault diagnosis and is removed over the winter period.

The complete system was tested at Ebre Observatory before its deployment at the Span- ish Antarctic Base. A new hut with a pier on which the fluxgate has been mounted has been built close to the original huts of LIV observatory (fig. 4). As noted in Section 2, a new Microcom model GTX-1.0 satellite transmitter was purchased and installed during the 20072008 survey, providing near real-time access to data. It uses the GOES_E link, the data files being retrieved from the Ottawa GIN. Up to now, the transmission is circa $99 \%$ reliable, and the downloaded data are available from Ebre Observatory web site (http://www.obsebre.es/). It is expected that all these improvements will facilitate the future inclusion of LIV in the list of INTERMAGNET magnetic observatories. 


\section{Transmission via ionospheric radio propagation}

From the communications point of view, the ionosphere is the layer of the atmosphere with enough ionization to significantly affect the propagation of radio waves. Since Marconi discovered that non-line of sight communications are possible by means of ionospheric reflections, this type of system has been widely used in many fields, e.g. military, diplomatic, aeronautics, amateur, etc.

In recent decades, the introduction of digital techniques to ionospheric radio systems has permitted the achievement of higher data rates and more robust modems. In this context, a new prototype called SANDICOM (Sounding System for Antarctic Digital Communications) has been developed (Vilella et al., 2005) with two main goals. Firstly, to measure the most significant parameters of the ionospheric radio link between the Spanish Antarctic Base and the Ebre Observatory. Secondly, to implement a new radiomodem specially designed for skywave communications from Antarctica, intended to transmit the information delivered by the geomagnetic observatory.

In addition to the usefulness of the link, the scientific interest of the project must be emphasized. Many papers in the literature, are related to oblique sounding. Most of them concentrate on single-hop links, e.g. Angling et al. (1998) for high-latitudes and Warrington and Stocker (2003) for mid-latitudes. Unfortunately similar analyses for very long distance links simultane- ously covering different latitudes in both hemispheres are rarely found. Although the results obtained from the sounding of such links are complex to interpret in terms of ionospheric physics, they may give valuable information of the overall ionospheric propagation.

Since SANDICOM was first deployed at the Spanish Antarctic Station in December 2003 (Vilella et al., 2005), the transceiver architecture has been improved to meet the requirements of the transmission. The current transceiver block diagram is depicted in fig. 5. More details can be found in Vilella et al. (2006). The emitter uses a 7.5 meter monopole in the 5 to 20 $\mathrm{MHz}$ band, which along with the antenna tuner assures a good impedance matching over the whole frequency range and the power amplifier gives up to 250 watts. The digital platform is based in a Virtex Field Programmable Logic Array (FPGA) from Xilinx, a Digital Up Converter (DUC), and a 14-bits D/A converter from Analog Devices. Thus, the waveform is digitally generated, with only amplification and filtering performed in the analog domain.

The receiver has been designed on the basis of a digital direct conversion architecture. A Variable Gain Amplifier (VGA) is used to adjust the received signal to the full scale-range of a 14-bits A/D converter. Then a Digital Down Converter (DDC) mixes the received channel to baseband, filters it and decimates the sampling frequency. It has been programmed using VHDL language. Finally the DDC output is transferred to a PC through a parallel port and stored for offline analysis.
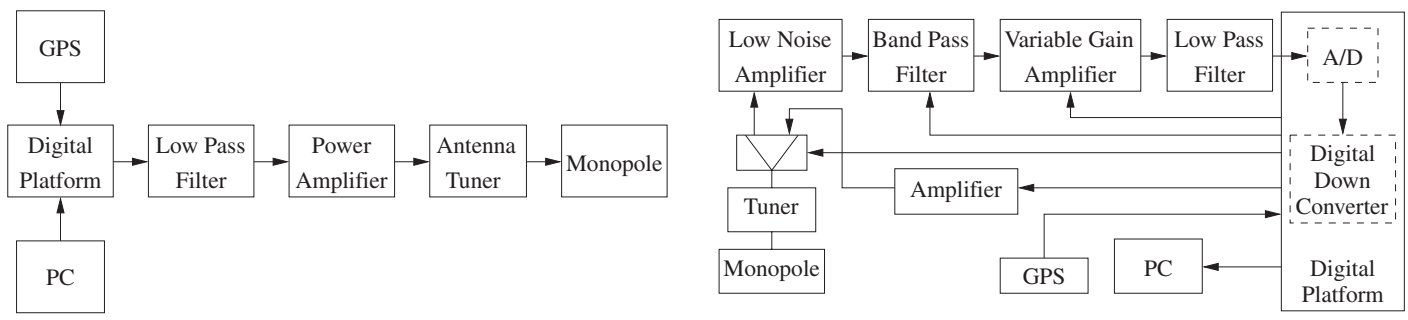

Fig. 5. Transmitter (left frame) and receiver (right frame) used for sounding and data transmission on the HF link. We note that the full transceiver is mainly digital, with only some filtering, amplification and antenna tuning performed in the analog domain. 


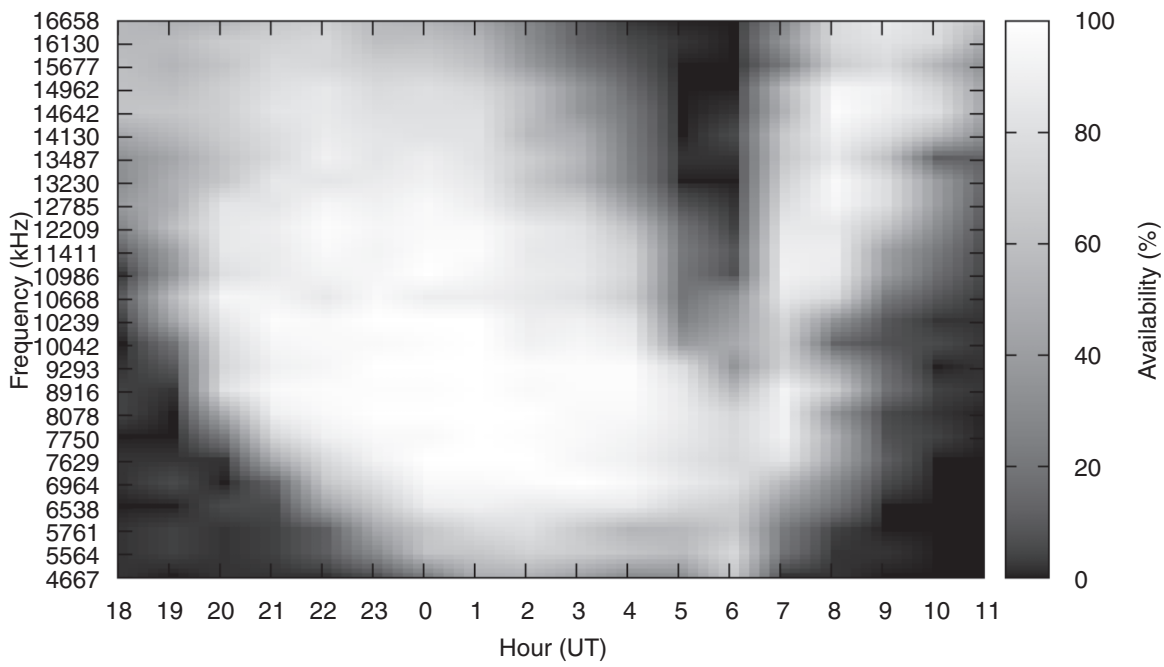

Fig. 6. Averaged link availability as a function of the hour and the frequency (adapted from Vilella et al., 2008).

This architecture was used first for the channel sounding and secondly for the data transmission. The channel was sounded on an hourly basis on 25 preselected frequencies from 5 $\mathrm{MHz}$ to $17 \mathrm{MHz}$. The dwell time at each frequency is around twenty seconds, including a narrowband sounding with a full power non modulated carrier and a wideband sounding based on a pulse compression technique using pseudo random noise sequences. The system has been run during the last three southern summers. The results in terms of availability, Signal to Noise Ratio (SNR) and time and frequency dispersion have been obtained and are discussed below.

The results of the link availability as a function of the hour and the frequency are shown in fig. 6. This result was obtained averaging through the 60 days of the 2006/07 survey. We note that, as expected, the lower frequencies propagate better at night whereas the higher frequencies perform better at sunset and at sunrise. Specifically, the best frequencies to establish the link between 20-22 UT and 6 UT are those below $12 \mathrm{MHz}$, whereas at sunrise and at sunset the frequencies above 12-13 MHz perform better.

Using the results taken from the availability measurements, the daily averaged SNR as a function of hour and frequency, using the bandwidth as a parameter, has been obtained. Although the SNR measurement is of limited scientific interest due to its strong dependence on the hardware used to probe the channel, it is a crucial result in order to design a data transmission system on that link. When the signal bandwidth is limited to $1 \mathrm{KHz}$, a large area between $8 \mathrm{MHz}$ and $13 \mathrm{MHz}$, and $0 \mathrm{UT}$ and $4 \mathrm{UT}$ with a SNR ranging from $-4 \mathrm{~dB}$ to $0 \mathrm{~dB}$ is observed.

Finally, the daily averaged multipath and Doppler spreads for every frequency and every hour have been obtained. The maximum multipath spread is normally observed at lower frequencies and rarely exceeds $2.5 \mathrm{~ms}$, whereas the minimum multipath occurs at higher frequencies with values below $0.75 \mathrm{~ms}$. On the other hand, the Doppler spread ranges between $1 \mathrm{~Hz}$ and $1.5 \mathrm{~Hz}$ with few exceptions. A more detailed discussion on the sounding results can be found in Vilella et al. (2008).

On the basis of these results, data transmission experiments have recently been carried out. From the sounding results derived from these new experiments, the most relevant channel characteristics for this link are: i) Negative SNR; ii) Dispersion both in time and in frequency; iii) Interference. We note that spread 


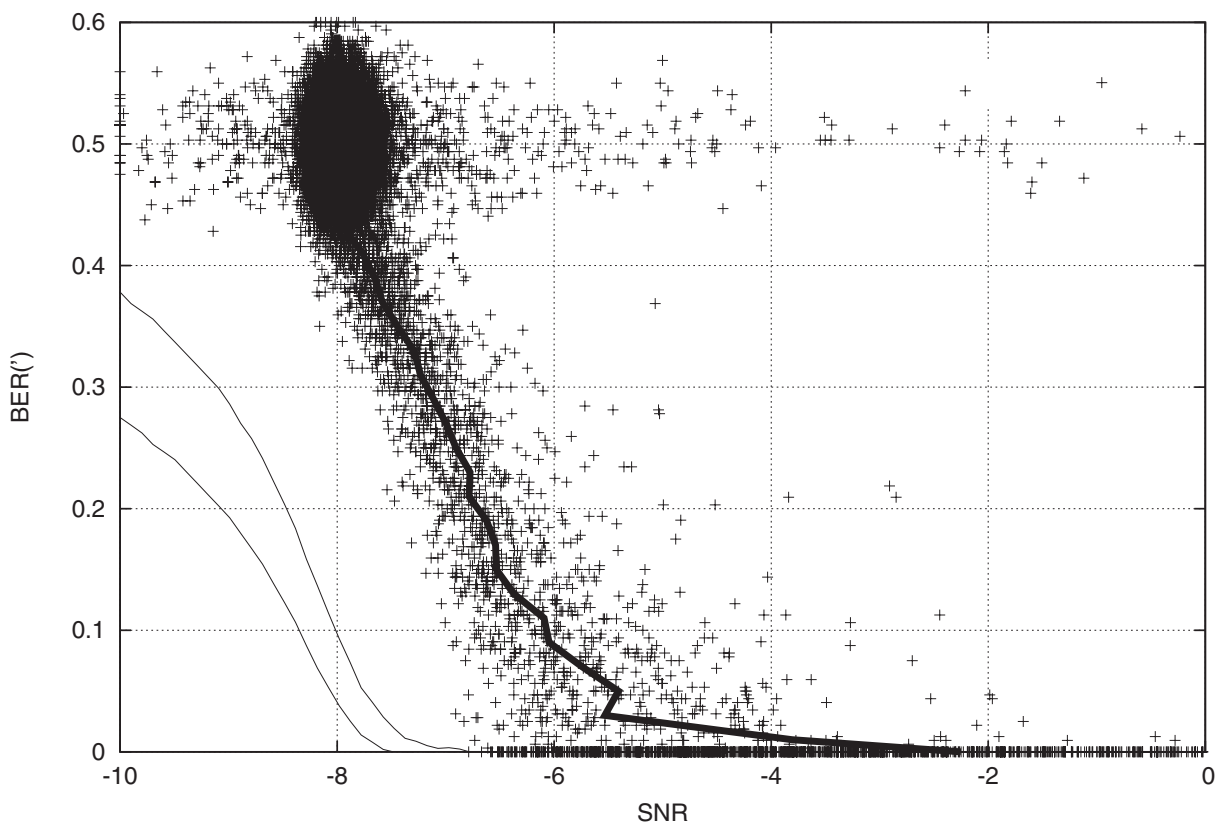

Fig. 7. A figure showing the preliminary results of the spread spectrum based data transmission system. A scatter plot of the Signal to Noise Ratio plotted against the Bit Error Rate (BER) measured in 320-bit bursts is depicted. Every cross corresponds to a single experiment.

spectrum techniques are a good choice to deal with these problems (Proakis, 1995).

Figure 7 is an example of the preliminary results obtained from the data transmission system. It shows a scatter plot of the Signal to Noise Ratio plotted against the Bit Error Rate (BER) measured in 320-bit bursts. Every cross represents a single experiment. The thick solid line is the median measured SNR to achieve a given BER and the two thin lines enclose the theoretical SNR interval to achieve a given BER with a $95 \%$ probability.

The configuration used to plot fig. 7 consists of: i) An interleaver and a rate-1/3 turbo coder; ii) An M-ary quadriphase spreader that selects two of the 64 available sequences of length 63-chips on the basis of a 10-bit coded block; iii) A QPSK modulator. This configuration delivers up to 198 bits per second when the chip rate is configured to $3125 \mathrm{~Hz}$.

We note that: i) This configuration is able to provide an almost error free data transmission for SNR above $-4 \mathrm{~dB}$; ii) Comparing theoretical and measured results, a $2-3 \mathrm{~dB}$ penalty is observed. This decrease of performance can be attributed to synchronization issues, non-Gaussian noise and/or fading.

Many other configurations with different chip rates, sequence lengths, code rates and modulations are being evaluated to meet the channel conditions and reach the maximum data rate without errors.

\section{Summary and conclusions}

The new LIV geomagnetic station includes both the former $\delta \mathrm{D} / \delta \mathrm{I}$ vector magnetometer, which ensures an acceptable thermal stability, and a new suspended tri-axial fluxgate magnetometer to guarantee a better mechanical stability and a faster sampling rate. A new system controlling both instruments has been developed, but the old one controlling just the $\delta \mathrm{D} / \delta \mathrm{I}$ 
magnetometer is still operative. Since both control systems were designed for low-power consumption, a possibility exists for leaving them running simultaneously during the long periods of unmanned operation, providing increased reliability in the event of instrument failure as data can be extracted from either system.

The experience gained during previous years operating and managing several automatic geomagnetic stations (Ebre Observatory, its remote satellite station at Horta de Sant Joan, and Livingston Island Observatory itself) suggested that the design and the development of the necessary software should be made by the research group itself. In this way better management of problems or future upgrades can be easily achieved, and at the same time allows control over the automatic transmission of the data providing better guarantees that transmissions, either via satellite or through the radio link currently under development, will operate reliably during the next surveys.

The ionospheric radio link has been shown to be a good alternative for low-rate data transmission from remote places. In this project, the feasibility of data transmission over the 12700 km link between the Spanish Antarctic Base and Ebre Observatory has been demonstrated. The proposed facilities for the data radio transmission may be of great use to facilitate lowcost, rapidly and easily accessible data from observatories located in remote areas or in developing countries which often provide very low noise sites (Rasson and van Loo, 2007). In this context, a semi-empirical method is being developed to predict the channel availability of the link using the vertical ionograms obtained at the Spanish Antarctic Base, at Ebre Observatory, and at other sites along the link.

\section{Acknowledgements}

This work has been carried out on behalf of the Spanish PN I+D+i Research Projects REN2003-08376-C02 and CGL2006-12437$\mathrm{C} 02$. The authors wish to express their sincere thanks to M. Ibáñez for his technical support and the Unidad de Tecnologías Marinas for their logistic support. This is IPGP contribution 2406.

\section{REFERENCES}

Angling, M.J., P.S. CANnON, N.C. Davies, T.J. WillinK, V. JODALEN and B. LUNDBORG (1998): Measurements of doppler and multipath spread on oblique high latitude HF paths and their use in characterizing data modem performance, Radio Science, 33 (1), 97-107.

Auster, H.U., M. Mandea, A. Hemshorn, E. Pulz and M. KORTE (2007): Automation of absolute measurement of the geomagnetic field, Earth Planets Space, 59, 10071014.

Catalán, M., L.M. Agudo and A. Muñoz (2006): Geomagnetic secular variation of Bransfield Strait (Western Antarctica) from analysis of marine crossover data Geophysical Journal International, 165 (1), 73-86.

De Santis, A., D. Di Mauro, L. Cafarella, R. D'Anna, L.R. Gaya-Piqué, P. Palangio, G. Romeo and R. Tozzi (2006): Deep seafloor magnetic observations under GEOSTAR project, Annals of Geophysics, 49 (2-3), 681-693.

García, A., I. Blanco, J.M. Torta, M. Astiz, J. Ibanez and R. ORTIZ (1997): A search for the volcanomagnetic signal at Deception volcano (South Shetland I., Antarctica), Annali di Geofisica, XL, 319-327.

INTERMAGNET (2008): INTERMAGNET Technical Reference Manual version 4.4, pp. 86 (available on line at http://www.intermagnet.org/publications/im_manual.pdf).

JANKOWSKI, J. and C. SUCKSDORFF (1996): Guide for magnetic measurements and observatory practice (IAGA, Warsaw), pp. 235.

Livermore, R.A., J.C. Balanyá, A. Maldonado, J.M. MartínEZ-MartíneZ, J. RodríGUEZ-FernÁndeZ, C. SANZ de GaldeAnO, J. Galindo-Zaldívar, A. JABaloy, A. Barnolas, L. Somoza, J. HernándezMolina, E. Surinach and C. Viseras (2000): Autopsy on a dead spreading center: The Phoenix Ridge, Drake Passage, Antarctica, Geology, 28, 607-610.

Maldonado, A., J.C. Balanyá, A. Barnolas, J. GalindoZALDÍvAR, J.R. HERNÁNDEZ, A. JABALOY, R.A. LiVERMORE, J.M. MARTÍNEZ-MartíneZ, J. RodRÍGUEZ-FeRNÁNDEZ, C. SANZ de Galdeano, L. Somoza, E. SurIÑACH and C. VisERAS (2000): Tectonics of an extinct ridge-transform intersection, Drake Passage (Antarctica), Mar. Geophys. Res., 21, 43-68.

MARSAL, S. and J.M. TORTA (2007): An evaluation of the uncertainty associated with the measurement of the geomagnetic field with a D/I fluxgate theodolite, Measurement Science \& Technology, 18, 2143-2156.

Marsal, S., J.M. Torta, J.J. Curto and J.G. Solé (2007a): Livingston Island Geomagnetic Observations, Antarctica, 2006 and 2006-2007 Survey. Observatori de l'Ebre. Roquetes, Tarragona (available on line at http://www.obsebre.es/php/geomagnetisme/boletin_liv ingston.php).

Marsal, S., J.M. TORTA and J.C. RIDDICK (2007b): An Assessment of the BGS $\delta \mathrm{D} \delta \mathrm{I}$ Vector Magnetometer, Pub1s. Inst. Geophys. Pol. Acad. Sc., C-99, 398, 158-165.

ProAkIs, J.G. (2001): Digital Communications, (McGrawHill, New York), pp. 1024.

RASSON, J.L. and S.A. VAN LOO (2007): New concepts in Geomagnetic Observatories Operation, Publs. Inst. Geophys. Pol. Acad. Sc., C-99, 398, 69-76. 
RidDick, J.C., C.W. TurbitT and J. McDonald (1995): The BGS Proton Magnetometer $(\delta \mathrm{D} / \delta \mathrm{I})$ Observatory Mark II System, Installation Guide and Technical Manual, British Geological Survey Technical report, WM/95/32. BGS Geomagnetism Series. Edinburgh.

TORTA, J.M. (2003): Una visión sobre el estado actual de la investigación en Geomagnetismo, Revista de Física, 17 (6), 47-51.

Torta, J.M., L.R. GAYA-PiQuÉ, J.C. RIDDICK and C.W. TuRBITT (2001): A partly manned geomagnetic observatory in Antarctica provides a reliable data set, Contributions to Geophysics and Geodesy, Geophys. Inst. Slov. Acad. Sci., 31, 225-230.

Torta, J.M., L.R. GAYA-PiQuÉ, J.G. Solé, I. Blanco and A. GARcía (1999): A new geomagnetic observatory at Livingston Island (South Shetland Islands): Implications for future regional magnetic surveys, Annali di Geofisica, 42 (2), 141-151.

UtADA, H. and H. SHIMIZU (2001): Geomagnetic observatories in the ocean hemisphere network project (OHP), IAGA-IASPEI Joint Sci. Ass. Abst. Book, p. 233.

VAN LOO, S.A. and J.L. RASSON (2006): Development of an automatic DI-Magnetometer, in Geomagnetics for Aeronautical Safety: a Case Study in and Around the Balkans, edited by J.L. RASSON and T. DELIPETROV (NATO Science Series Publication), pp. 177-186.

Vilella, C., D. Miralles, J.C. Socoró, J.L. Pijoan and R. AQuilú́ (2005): A new sounding system for HF digital communications from Antarctica, in Proc. International Symposium on Antennas and Propagation.

Vilella, C., P. BergadÀ, M. Deumal, J.L. PijoAn and R. AQUILUÉ (2006): Transceiver architecture and Digital Down Converter design for long distance, low power HF ionospheric links, in Proc. Ionospheric Radio Systems and Techniques, July 2006, 95-99.

Vilella, C., D. Miralles and J.L. Pijoan (2008): An Antarctica-to-Spain HF ionospheric radio link: Sounding results, Radio Science, 43, RS4008, doi:10.1029/2007RS003812.

WARrington, E.M. and A.J. STOCKER (2003): Measurements of the Doppler and multipath spread of the HF signals received over a path oriented along the midlatitude trough, Radio Science, 38 (5), doi:10.1029/2002RS002815. 